CORRIGENDA

\title{
Additive effects of Artemisia capillaris extract and scopoletin on the relaxation of penile corpus cavernosum smooth muscle
}

BR Choi, SK Kumar, C Zhao, LT Zhang, CY Kim, SW Lee, J-H Jeon, I So, SH Kim, NC Park, HK Kum and JK Park

International Journal of Impotence Research (2016) 28, 80; doi:10.1038/ijir.2016.1

Correction to: International Journal of Impotence Research (2015) 27, 225-232; doi:10.1038/ijir.2015.23; published online 8 October 2015
For the above referenced article, there was an error with one author's name. The correct name is 'KK Soni'.

\section{Factors predicting outcomes of penile rehabilitation with udenafil $50 \mathrm{mg}$ following radical prostatectomy}

TH Kim, Y-S Ha, SH Choi, ES Yoo, BW Kim, S-J Yun, W-J Kim, YS Kwon and TG Kwon

International Journal of Impotence Research (2016) 28, 80; doi:10.1038/ijir.2016.9

Correction to: International Journal of Impotence Research (2016) 28, 25-30; doi:10.1038/ijir.2015.28; published online 29 October 2015

For the above referenced article, there was an error in the first institution's name. The full affiliation should read:
${ }^{1}$ Department of Urology, School of Medicine, Kyungpook National University, Daegu, South Korea

Also, the corresponding author information should be changed to:

Department of Urology, Kyungpook National University Medical Center, 807 Hoguk-ro, Buk-gu, Daegu 702-210, South Korea. 